Proceedings

\title{
The Effect of Pt Decoration on the Gas Sensing Properties of Copper Oxide Nanorods ${ }^{\dagger}$
}

\author{
Neslihan Sarıca *, Onur Alev and Zafer Ziya Öztürk \\ Department of Physics, Gebze Technical University, Kocaeli 41400, Turkey; onuralev@gtu.edu.tr (O.A.); \\ zozturk@gtu.edu.tr (Z.Z.Ö.) \\ * Correspondence: nsarica@gmail.com; Tel.: +90-2626051324 \\ † Presented at the Eurosensors 2018 Conference, Graz, Austria, 9-12 September 2018. \\ Published: 10 December 2018
}

\begin{abstract}
Herein, copper oxide nanorods were hydrothermally synthesized on $\mathrm{SiO}_{2}$ substrates with inter digital gold electrodes fabricated by photolithography method. This method offers the advantage of practical usage as a sensor device. Hydrothermal synthesis were carried out at $85{ }^{\circ} \mathrm{C}$ for $4 \mathrm{~h}$. Fabricated nanorods were decorated with Pt for $30 \mathrm{~s}$ via magnetron sputtering system. SEM, XRD and EDX studies were performed to characterize the samples. Sensing properties of nanorods were tested with $\mathrm{H}_{2}, \mathrm{NO}_{2}$ and $\mathrm{CO}$ at $200{ }^{\circ} \mathrm{C}$. Results showed that $\mathrm{Pt}$ decoration enhanced sensor response to $\mathrm{H}_{2}$ while decreasing sensor response to $\mathrm{NO}_{2}$ and $\mathrm{CO}$.
\end{abstract}

Keywords: gas sensor; copper oxide; hydrothermal

\section{Introduction}

Semiconductor metal oxides take an important part as a sensing layer for gas sensor applications due to their superior properties such as selectivity and stability [1]. Moreover, sensing properties of metal oxides can be enhanced by tailoring the surface morphology, metal doping or loading [2]. Although $\mathrm{p}$ type metal oxides for gas sensor applications are very limited, $\mathrm{p}$ type copper oxide shows promising gas sensing properties [3] and deserves further investigation.

In this study, copper oxide nanorods were hydrothermally synthesized on IDE (inter digital electrode) precoated $\mathrm{SiO}_{2}$ substrate. In order to examine the effect of Pt decoration on gas sensing properties of $\mathrm{CuO}$ nanorods, they were decorated with $\mathrm{Pt}$ via RF magnetron sputtering in argon atmosphere at $5.3 \times 10^{-3}$ mbar. Pure Pt target was used to decorate $\mathrm{CuO}$ nanorods for $30 \mathrm{~s}$ under $75 \mathrm{~W}$ DC power. Gas sensing properties of pristine and decorated nanorods were tested against $\mathrm{H}_{2}, \mathrm{CO}$ and $\mathrm{NO}_{2}$ gases.

\section{Experimental}

\subsection{Synthesis and Characterization of Cuo Nanorods}

Firstly, $\mathrm{SiO} 2$ substrates were coated with gold IDE on its surface. Before hydrothermal synthesis, $10 \mathrm{mM}$ ethanolic copper (2) acetate monohydrate $\left(\mathrm{CH}_{3} \mathrm{COO}\right)_{2} \mathrm{Cu}^{*} \mathrm{H}_{2} \mathrm{O}$ solution was used to form seed layer by spin coating system instead of wetting. After seed layer formation these substrates were placed inside a Teflon beaker containing $25 \mathrm{mM}$ copper nitrate trihydrate $(\mathrm{Cu}(\mathrm{NO} 3) 2 \cdot 3 \mathrm{H} 2 \mathrm{O})$ and 25 $\mathrm{mM}$ hexamethylenetetramine aqueous solution at $85^{\circ} \mathrm{C}$ for $4 \mathrm{~h}[4]$.

SEM (Philips XL 30 S), EDX and XRD (Philips 1820 X-Ray Diffractometer) were used to perform morphological and structural characterization respectively. 


\subsection{Sensor Measurements}

Sensing measurements were performed in a $1 \mathrm{~L}$ homemade chamber under $200 \mathrm{sccm}$ high purity dry air flow at $200{ }^{\circ} \mathrm{C}$ controlled by a Lakeshore 340 temperature controller. $0.05 \mathrm{~V}$ constant bias voltage was applied to samples and direct current was measured with Keithley 6517 A Electrometer/ High Resistance Meter. When the steady state was obtained, samples were exposed to desired concentrations of $\mathrm{H}_{2}, \mathrm{NO}_{2}$ and $\mathrm{CO}$ controlled via multi gas controller device (MKS 647C).

Sensor responses of samples against reducing gases $\left(\mathrm{H}_{2}\right.$ and $\left.\mathrm{CO}\right)$ and oxidizing gases $\left(\mathrm{NO}_{2}\right)$ were calculated according to the below equations respectively [3,5];

$$
\begin{aligned}
& \text { Sensor Response }=\left(\mathrm{I}_{0}-\mathrm{I}_{\mathrm{g}}\right) / \mathrm{I}_{\mathrm{g}} \\
& \text { Sensor Response }=\left(\mathrm{I}_{\mathrm{g}}-\mathrm{I}_{0}\right) / \mathrm{I}_{0}
\end{aligned}
$$

Io represents the current of the baseline and $I_{g}$ is the minimum or maximum current value of the sensor when the sample is exposed to reducing or oxidizing gases respectively.

\section{Results and Discussions}

Fabricated nanorods with very thin diameter are shown in Figure 1a. Peaks seen in XRD graph (Figure 1b) can be attributed to the monoclinic $\mathrm{CuO}$ phase [4]. EDX study on Pt decorated copper oxide nanorods confirms the presence of $\mathrm{Pt}$ (data not shown).

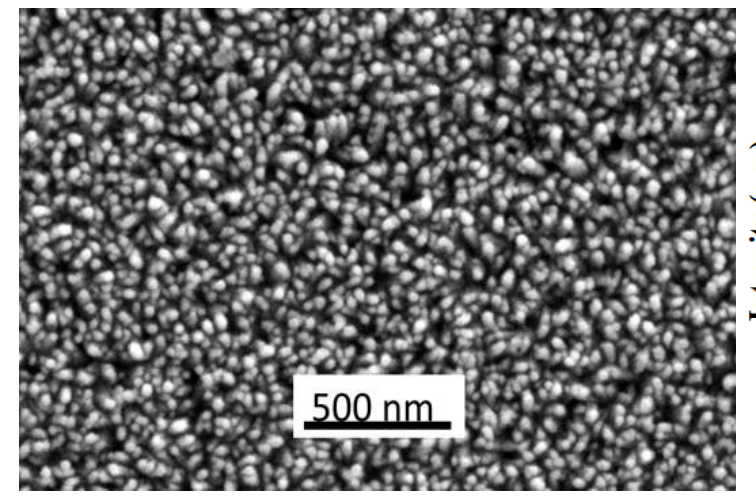

(a)

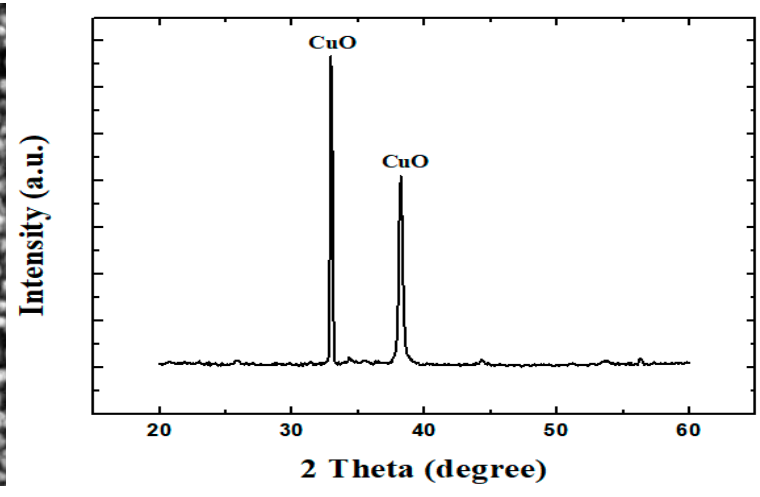

(b)

Figure 1. (a) SEM image of $\mathrm{CuO}$ nanorods; (b) XRD graph of $\mathrm{CuO}$ nanorods.

Gas sensing properties of pristine and decorated $\mathrm{CuO}$ nanorods were tested against $1000 \mathrm{ppm}$

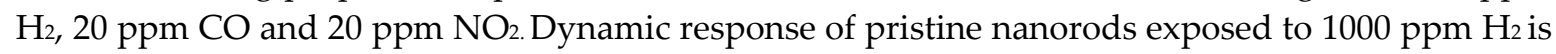
shown in Figure 2. According to the sensing results as illustrated in Figure 3, pristine nanorods show the highest sensor response to $1000 \mathrm{ppm} \mathrm{H}_{2}$. It is also seen that sensitivity of pristine nanorods against $20 \mathrm{ppm} \mathrm{NO} \mathrm{N}_{2}$ is higher than $20 \mathrm{ppm}$ CO. In the case of Pt decoration, decorated nanorods show higher sensitivity to $\mathrm{H}_{2}$ compared to the pristine one due to the chemical sensitization via spillover effect of Pt. On the other hand, sensor responses to $\mathrm{NO}_{2}$ and $\mathrm{CO}$ decrease thus, it can be said that selectivity to $\mathrm{H}_{2}$ is increased by $\mathrm{Pt}$ decoration. In addition to this result, sensor responses of pristine and decorated nanorods against $\mathrm{NO}_{2}$ also increase with increasing concentrations of $\mathrm{NO}_{2}$. 


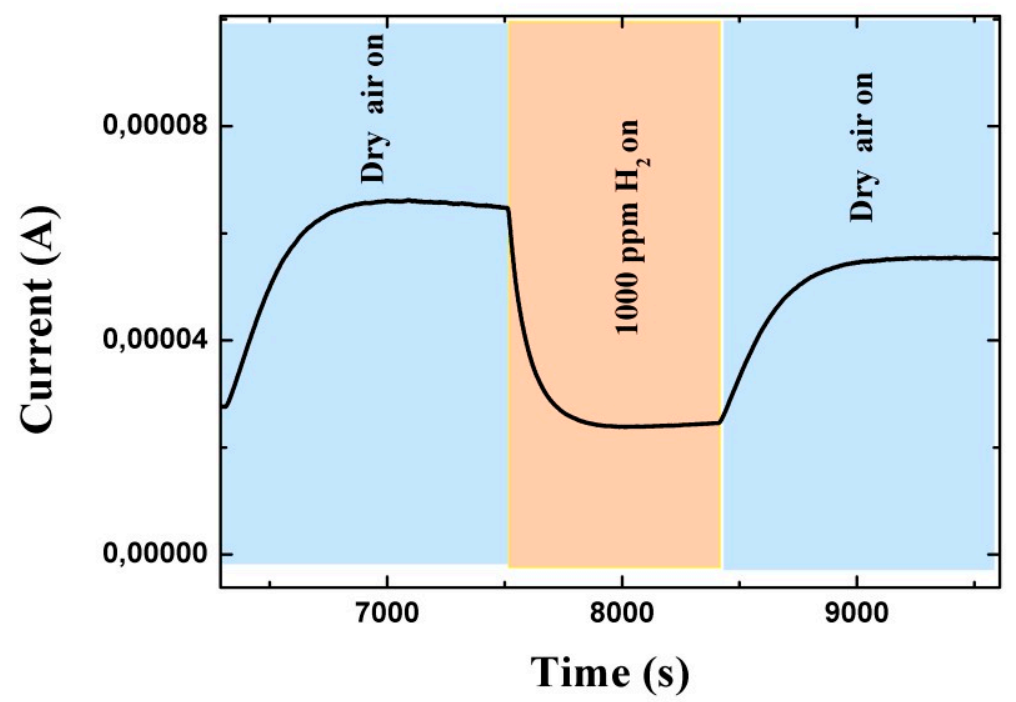

Figure 2. Dynamic sensor response of pristine $\mathrm{CuO}$ nanorods exposed to $1000 \mathrm{ppm} \mathrm{H}_{2}$.

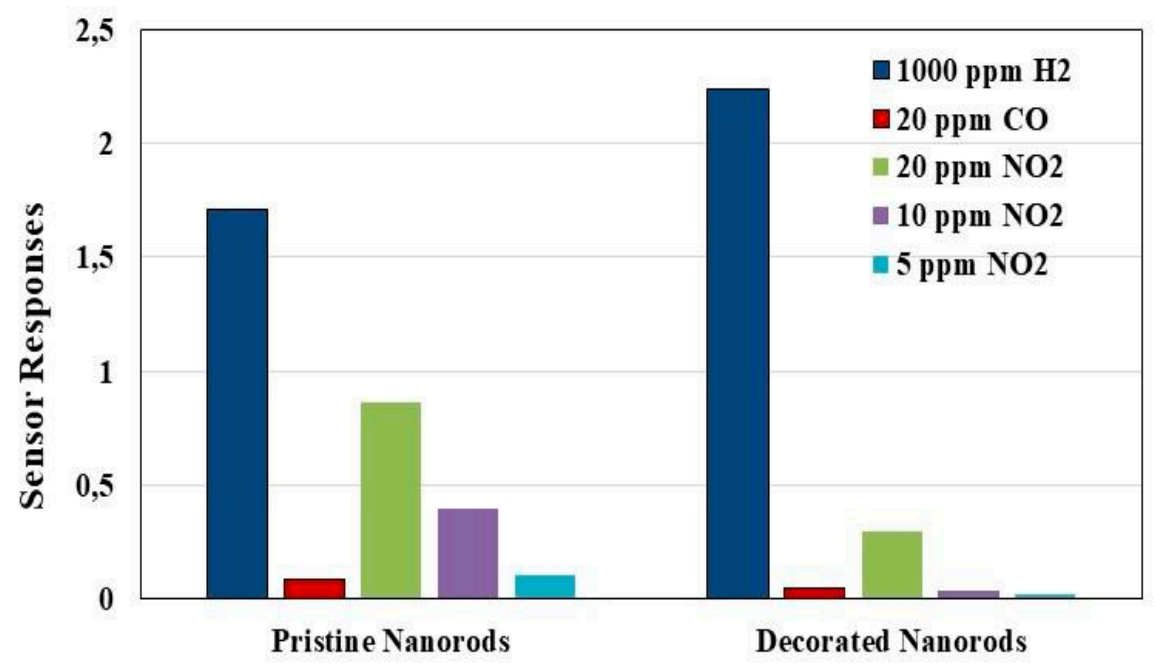

Figure 3. Sensor responses of pristine and decorated $\mathrm{CuO}$ nanorods againts $\mathrm{H}_{2}, \mathrm{CO}$ and $\mathrm{NO}_{2}$.

\section{Conclusions}

In this study, copper oxide nanorods were directly grown on IDE coated $\mathrm{SiO}_{2}$ substrates. In order to examine the effect of $\mathrm{Pt}$ decoration on sensitivity, nanorods were decorated with $\mathrm{Pt}$ for $30 \mathrm{~s}$ by $\mathrm{RF}$ magnetron sputtering. Sensing measurements of pristine and decorated nanorods showed that $\mathrm{Pt}$ decoration increased sensitivity to hydrogen while decreasing sensitivity to $\mathrm{CO}$ and $\mathrm{NO}_{2}$. Thus, these positive effects of $\mathrm{Pt}$ decoration on nanorods provide a sensitive and selective $\mathrm{H}_{2}$ gas sensors.

Author Contributions: Z.Z.Ö. designed the experiments; N.S. and O.A. performed the experiments; N.S. and O.A. analyzed the data; N.S. wrote the paper. All authors discussed the results and contributed to the final manuscript.

Funding: This work has been partly funded by the Scientific and Technological Research Council of Turkey (TUBITAK) project number 116M201.

Conflicts of Interest: The authors declare no conflict of interest. 


\section{References}

1. Şişman, O.; Kılınç, N.; Öztürk, Z.Z. Structural, electrical and $\mathrm{H}_{2}$ sensing properties of copper oxide nanowires on glass substrate by anodization. Sens. Actuators B Chem. 2016, 236, 1118-1125.

2. Mirzaei, A.; Kim, J.H.; Kim, H.W.; Kim, S.S. Resistive-based gas sensors for detection of benzene, toluene and xylene (BTX) gases: A review. J. Mater. Chem. C 2018, 6, 4342-4370.

3. Zappa, D.; Comini, E.; Zamani, R.; Arbiol, J.; Morante, J.R.; Sberveglieri, G. Preparation of copper oxide nanowire-based conductometric chemical sensors. Sens. Actuators B Chem. 2013, 182, 7-15.

4. Liu, L.; Hong, K.; Hu, T.; Xu, M. Synthesis of aligned copper oxide nanorod arrays by a seed mediated hydrothermal method. J. Alloys Compd. 2012, 511, 195-197.

5. Şişman, O.; Kılınç, N.; Öztürk, Z.Z. H2 Sensing Properties of $\mathrm{Cu}_{2} \mathrm{O}$ Nanowires on Glass Substrate. Procedia Eng. 2015, 120, 1170-1174.

(C) 2018 by the authors. Licensee MDPI, Basel, Switzerland. This article is an open access article distributed under the terms and conditions of the Creative Commons Attribution (CC BY) license (http://creativecommons.org/licenses/by/4.0/). 